\title{
Study on Strategy of Integrative Development of Yantai Old and New Media
}

\author{
Yajie Sang \\ Yantai Nanshan University \\ Yantai, Shandong, China 265713
}

\begin{abstract}
As we all know, the recent decade is the golden age of Yantai cultural and creative industries to fl ourish. Since the booming of Internet in Yantai, the survival and development of local traditional media of Yantai has become a hot topic. And with the development of mobile Internet and the popularization of mobile smart terminal, the transformation of Yantai local traditional media and integrative development of old and new media have aroused more and more concern and attention. However, some of the traditional media are still struggling to seek the direction and path of transformation and integrative development Yantai local traditional media, while some small and medium-sized media that believe the market environment is poor with hopeless transformation have been defeated firstly, parting from the best yet the worst times in the eyes of media people in advance, arousing sighing and sorrow within the industry. Therefore, corresponding strategies for resolving problems exist in integrative development of old and new media in Yantai shall be proposed according to its current situation and dilemma, and the market thinking suitable for that integrative development shall be established to better bring out media products and services with local characteristics of Yantai.
\end{abstract}

Keywords-old and new media; integrative development; strategy research

\section{CURRENT ST ATUS OF INTEGRATIVE DEVELOPMENT OF YANT AI OLD AND NEW MEDIA}

\section{A. Development of New Media to Promote Transformation of Traditional Media}

Yantai Broadcasting and TV Station and Yantai Daily Media Group is the important news consensus spreading institutions in Yantai, and such media organizations as television media, broadcasting media, newspapers media, online media and others, with the functions of spreading news, public service information, publicity and other entertainment program function, which are the main channels for Yantai public to obtain local information. Today, under the new media age, the community is a "correspondent" but also a "reporter". As for the timeliness of the occurrence of news, it has the characteristics of more convenient and faster than professional journalists, although compared to traditional media, the news described by professional journalists is more objective and credible. However, in the "era of fingers", the new facts formed by the information pieces hold by the public seem to be more suitable for the tastes and habits of network or the mobile Internet circles. And the follow-up reports relying on the new media or mobile Internet are more intuitive and shocking than traditional TV and newspapers. For this reason, Yantai traditional media is undergoing a severe test. Through reconfiguring of the news resources and news reporting, traditional media and new media will gradually realize the sharing of news resources and real-time reports, thus to obtain a win-win result of old and new media. At the same time, it promotes the traditional media and new media in Yantai to provide greater convenience for the community to participate in public affairs and news coverage, but also makes the integration of old and new media in Yantai develop towards the win-win direction.

\section{B. Integration of Old and New Media to Enter into All- Media Era}

The integration of old and new media in all-media era is to combine together different forms of media in Yantai, such as television, Internet, newspapers, magazines, mobile Internet and so on, to achieve sharing of various media resources to a greater extent, thereby forming the all-media communication framework system of Yantai. And the formation and development of all-media communication framework system has further adapted to the communication needs of news and instant messages under different environments by different communication subjects or the same communication subject, playing an important role of supervision in promoting transparency of news and credibility of news agencies in Yantai, and also helps the establishment and shaping of news communication department's public image.

The integration of old and new media in the all-med ia era shall be conducted from two aspects. The first is to give play to the precision of news resources gathered by Yantai traditional media in combination with the advantages of new media such as faster transmission speed and wide path, to establish all-media news gathering center and to make it the best platform for old and new media's integration development. The second is to strengthen and improve the working mode of existing news gathering staff through training of the skills of using new media by Yantai traditional media staff, thus they can not only complete the task of traditional media coverage, but also shoulder the responsibility of uploading information to the new media and social circles for immediate release. And no matter 
traditional media or new media, the news communication concept should always be the "content is king", and to conduct news information production for different news according to characteristics of different media and the demands by virtue of all-media platform, to make Yantai traditional media gradually evolve into an all-media integration of traditional $\mathrm{TV}$, journals media, news information site, APP application terminal in the field of news information communication. Therefore, "content is king" is still the best way for Yantai traditional television, journals media and new media to expand the communication path and improve the audiences' reading range in all-media era.

\section{DILEMMA OF INTEGRATIVE DEVELOPMENT OF OLD AND NEW MEDIA IN YANT AI}

\section{A. Unclear Ultimate Goal of Old and New Media Integration}

The rapid development of new media technologies in Yantai and widespread popularity of finger social circle in young generation have made the development speed of new media technology be greatly underestimated by traditional media. And Yantai traditional media lacks depth study of new media technology while studying transformation direction which has led to the unclear integration goal of old and new media, while their research ideas and practice are obviously falling behind with respect to the characteristics of newly developed young group thinking. And the differences between management methods of existing traditional media and new media as well as the integration concept of old and new media are fully reflected in the differences between traditional media with a concept of "content is king" and the inclusive new media, and the differences between production cycle of traditional media and the rapid speed and range of new media. Therefore, these two kinds of differences have caused the inconsistent goal of the integration of traditional media and new media in Yantai.

\section{B. Staff's Professional Quality being Lagged Behind}

Yantai traditional media has experienced a long period of development, and the professional quality of its staff has already developed quite mature, with their business processes and efficiency fully meeting the development requirements of traditional media. But with the popularization and application of new media technology in Yantai, those compound talents with new media knowledge and technology are short of adequate understanding of traditional media. This also resulted in absence of effective connection in the process of old and new media integration in Yantai, influencing the scientific positioning of old and new media integration concept and the formulation of clear and effective strategy of integration development.

\section{IMPLEMENTATION STRATEGY OF INTEGRAT IVE DEVELOPMENT OF YANT AI OLD AND NEW MEDIA}

Contents have always been a fundamental factor for Yantai local traditional media. However, the rapid development of Internet has changed the rules and business logic of information dissemination, so clinging to "content is king" will be destined an important part of the reas on why Yantai local traditional media is unable to survive. Even so, Yantai local traditional media cannot abandon content which is a special skill advantage. Perhaps transforming traditional media content positioning and production organization using new Internet thinking, operating competitive content products on new platform, and reconstructing traditional media's business mode with Internet thinking is a worthwhile way. Yantai Daily Media Group is the leader of Yantai local traditional media. Within the all-media framework, the strategy of activating all media cluster through in-depth integration of media, realizing complementary communication of different media according to the law of communication, completing seamless coverage of audiences' fragmentation time, is undoubtedly an in-depth attempt for conducting reform in traditional media. However, under the new situation of a fundamental change in communication environment, to conduct reform for such traditional media as Yantai Daily Media Group will not only face the change of audience reading habits, gradually shifting of reading platform, news distribution channel's increasingly importance, but also will face the harsh reality of dwindling readers of traditional media and deteriorating business performance. Therefore, Yantai traditional media shall first change the thinking mode in terms of concept, and secondly to build a new platform using the Internet thinking and to remodel content positioning and production processes, in order to truly realize the integration development of old and new media in Yantai, and transform the content advantages of traditional media into product advantages of new media with business mode.

In summary, as for the integration of old and new media in Yantai, while exploring transformation in combination with Yantai Broadcasting and TV Station and Yantai Daily Media Group, I believe that the implementation strategy of old and new media integration and development shall focus on cultivation and establishment of market thinking mode. So, the cultivation and establishment of market thinking shall include the following aspects: platform thinking; free thinking; user thinking; products thinking.

\section{A. Establish Communication Platform}

To successfully build multip licity of Yantai old and new media's integrative development, in my opinion, new media in Yantai shall grow bigger and stronger on the basis of existing communications platform, and establish their own proprietary communications platform. In fact, Yantai traditional media itself is a platform, but with the development of desktop Internet and mobile Internet, this platform is shrinking with its value being derogated. Based on this, Yantai traditional media must create their own new online platform, to form their own network entry, as the old and new media cannot establish influence without their own communications platform, and cannot gather users and flow, let alone to cash users and flow. Therefore, the communication platform construction is imperative for Yantai traditional media currently. With the development of mobile communication technology and popularity of mobile 
intelligent terminal, the platform for general public to obtain information is gradually transferred to the mobile Internet. In order to adapt to this changing trend, Yantai traditional media should invest the limited funds and resources to the construction of mobile Internet communication platform. And if the limited funds and resources are continuously being invested into desktop Internet too much, there won't be much revenue.

According to the experience of successful Internet enterprises, they are always good at and strive to create an inclusive, open and win-win sharing platform. As for Yantai traditional media desiring to seek transformation, platform is not only the media content publishing place, but also the place for audiences to participate in news production and news service acquisition, and even the communication carrier for Yantai traditional media to gather users, obtain flow and ultimately gain revenue. Conversely, Yantai media communication platform shall be constructed according to their own capabilities. In the absence of sufficient funds, technology and management to develop new communication platform, the use of such public technology platforms as MicroBlog and WeChat, or to conduct redevelopment using the open interfaces of public platforms, perhaps is also a good marketing strategy.

\section{B. Improve Product and Service}

The products and services of communication platform of Yantai old and new media's integrative development shall be offered for free, whereby to accumulate the number of users, improve user experience and to cultivate user's behavior habits. According to the experiences of free products and services of such successful Internet companies as Qihoo 360 and Tencent QQ, in order to develop and establish the user's path dependence, they continuously accumulate quantity of users and enhance the user experience through optimization and upgrading of products and services for free. As for traditional media holding the concept of "content is king", the largest source of revenue is the sales of content. But with the large-scale application of communication platform for free, such charging mode may ultimately not be successful, as it goes fare gradually from the spirit of Internet, and it is a departure from user habits. Therefore, the free Internet model is an inexhaustible driving force for sustainable development.

\section{Meet the User's Needs and Experience}

The communication platform of Yantai old and new media's integrative development shall put user's needs and experience on the most important position. In the mobile Internet era, the products and services developed by companies shall have accurate positioning of user needs, meet the user experience and create value for customers, thus they will be recognized by the users. Therefore, the communication platform of Yantai old and new media's integrative development must put the user's needs and experience on the most important position, with specific methods of transforming the traditional media using Internet thinking and marketing mode and changing the one-way communication pattern of traditional media to adapt to different user needs and experience, and make tailored information products for them. And not like before, regardless of users' need, a pile of useful or useless information will be offered. In addition, the communication path of platform can not be one-way, but shall obtain users' feedback on products and services in the interaction with products and services, adjust and improve products and services in a timely manner to satisfy the needs of users to the largest extent, and build the business mode for product and service updates from users' demand. With the advent of mobile Internet era, the value of news portal is undergoing a step by step devaluation, and the era of portal winner-take-all has past. Its business mode is also facing challenges, therefore, the user's needs and experience are the most important factors in building the communication platform of old and new media's integrative development.

\section{Establish Product Thinking}

The communications platform of Yantai old and new media's integrated development shall establish a product thinking to provide users with better products and services. When the quantity of users and flow of communication platform has reached a certain degree, it will definitely cause a qualitative change, at this time, in addition to advertising, if no interface of communication platform is reserved, users and flow cannot automatically transfer into business value. At the beginning of research, the communications platform of old and new media's integrative development must have a clear design of its business mode. Just as aforementioned, content positioning of business mode can be deduced from the reverse direction according to the property of products and services, such as advertising, offline activities, $\mathrm{O} 2 \mathrm{O}$ and so on. In addition, in the mobile Internet era, the localized social products and services with sever verticalization are most suitable to be operated on the communication platform of old and new media's integrative development. On the one hand, these products and services are easier to meet the general public demands for information and services, which is helpful to enhance user stickiness; on the other hand, the social product and service with severe verticalization have clear targeted users, which is beneficial to conduct activities both online and offline, absorbing the advertising investment which belongs the same field with products and services, thus to achieve the business mode of products and services.

The generation of good products by communication platform of Yantai old and new media's integrative development, is not only beneficial to retain existing users, but also can attract new users with low cost or zero cost, because in the social era of self-media, good products and services will speak, and be capable of self-spreading. And as for Yantai traditional media people, it is critical to have product and service thinking, to meet the individual needs of different groups of people. Therefore, the establishment of communication platform of Yantai new and old media's integrative development is a research and development of the unique information products and services. Only by this way, can the content advantages be transferred into the advantage of information products and services with a business mode. 


\section{CONCLUSION}

The integrative development of old and new media in Yantai not only complies with the demands of Chinese informatization and modernization, but also conforms to the public perception of integrative development of old and new media in Yantai. Therefore, in order to adapt to the new situation and requirements of Yantai old and new media integration, we shall make full sense of the management ideas, competition and cooperation, integration and division of labor, content and form and other aspects of traditional media and new media, and effectively improve the level of Yantai old and new media integration, so as to ultimately serve the public of Yantai.

\section{REFERENCES}

[1] Lu Fengiaio. Integration of Old and New Media in All-Media Era. JIN TIAN. 2012(08).

[2] Li Qiang. New Media: Strong Competitor against Traditional Media. Journalism Lover. 2010(08)

[3] Tang Yushi. How Traditional Media Response to Transformation in New Media Age. Science \& Technology for China's Mass Media. 2010(08).

[4] Gao Yiming. Integration and Complementation of Traditional Media and New Media. Journalism \& Communication. 2010(01)

[5] Wen Weiwei. Dilemma and Solution of Television News under New Media Environment. Journalism Lover. 2011 (20). 